\title{
Mechanical Properties of Particulate Reinforced Titanium-based Metal Matrix Composites Produced by the Blended Elemental P/M Route
}

\author{
Masuo HAGIWARA, Nobuhiro ARIMOTO, ${ }^{1)}$ Satoshi EMURA, Yoshikuni KAWABE and Hirowo G. \\ SUZUKI ${ }^{2)}$
}

Mechanical Properties Division, Tsukuba Laboratories, National Research Institute for Metals, Sengen, Tsukuba, Ibaraki-ken, 305 Japan. 1) Research and Development Center, Osaka Titanium Manufacturing Co., Higashihama-cho, Amagasaki, Hyogo-ken, 660 Japan. $\quad 2$ 2) Stainless Steel and Titanium, Steel Research Laboratories, Nippon Steel Corporation, Shintomi, Futtsu, Chiba-ken, 299-12 Japan.

(Received on March 16, 1992; accepted in final form on May 22, 1992)

\begin{abstract}
The titanium-based metal matrix composites (MMC) reinforced with relatively large-sized ceramic particulates have been produced by the blended elemental (BE) $\mathrm{P} / \mathrm{M}$ route. The extra low chlorine titanium powder, $\mathrm{Al}_{3} \mathrm{Ti}$ master alloy powder, and $\mathrm{FeB}$ and $\mathrm{Cr}_{3} \mathrm{C}_{2}$ ceramic powders were used as starting materials. The dispersion of either $\mathrm{TiB}$ or $\mathrm{TiC}$ particulate reinforcements in the matrix were therefore made in situ during the sintering process. The distribution of particulate reinforcements in the matrix was reasonably random. Tensile tests were done at temperatures up to $923 \mathrm{~K}$. It has been found that the tensile strength of these composites are superior to those of the unreinforced matrix alloys in the whole temperature ranged examined. The elastic modulus was also increased by the presense of these ceramic reinforcements. No ductility was found for both composites at room temperature, but some ductility was observed at temperatures above $623 \mathrm{~K}$. These observations were interpreted in terms of the failure mechanisms observed using scanning electron microscopy.
\end{abstract}

KEY WORDS: metal matrix composites, titanium alloy, powder metallurgy, ceramic particulates, tensile strength.

\section{Introduction}

Titanium alloy are ideally suited for airframe and gas turbine engine components because of their unique combination of mechanical properties. One of drawbacks of titanium alloys is that the service temperature is limited to $873 \mathrm{~K}$ due to a degradation of creep strength, metallurigical stability and environmental resistance. ${ }^{1)}$

Titanium aluminides are receiving increased attention for application as high performance materials but these alloys are intrinsically brittle, and success in improving low temperature ductility while maintaining high temperature mechanical properties has been limited.

However, for future aircraft design, there is still a demand for high temperature titanium alloys having superior combinations of tensile strength, creep resistance, stiffness, corrosion resistance and thermal stability compared to conventional alloys in the temperature range between 873 and $1273 \mathrm{~K}$.

Fabrication of titanium-based metal matrix composites (MMC) creates considerable potential for improvement in various mechanical properties, particularly in stiffness and strength. There are two basic types of MMC, i.e., long fiber reinforced and particulate reinforced. Of these, development activities are currently centered around SCS-6 fiber reinforced $\mathrm{MMC}^{3-6)}$ but these are highly anisotropic in properties and fabrication is complex and expensive. Interest has increased in ceramic particulate reinforced $M M C$ in recent years because these have isotropic characteristics and can be processed more cheaply using conventional technologies such as ingot metallurgy, ${ }^{7}$ casting ${ }^{8-9)}$ and powder metallurgy. ${ }^{10-14)}$

Blended elemental $(\mathrm{BE})$ powder metallurgy $(\mathrm{P} / \mathrm{M})$ has been considered to be one of the most attractive net shape technologies ${ }^{15)}$ for producing various types of titanium-based MMC with tailored microstructures. The pioneering work in this field was carried out by Abkowitz of Dynamet Technology Inc., who first developped a Ti-6Al-4V matrix composite reinforced with TiC particulates. ${ }^{12)}$ However, mechanical property data available for the $\mathrm{P} / \mathrm{M}$ processed $\mathrm{MMC}$ are still lacking. Particularly, high temperature tensile data and comparison with the unreinforced matrix alloy have received relatively little attention.

In the present study, titanium allow-based MMC containing relatively large-sized ceramic particulates have been produced by the proprietary $\mathrm{BE} \mathrm{P} / \mathrm{M}$ route. The details of the fabrication and the results of the microstructural characterization and the high temperature tensile tests done on the composites and matrix alloy 


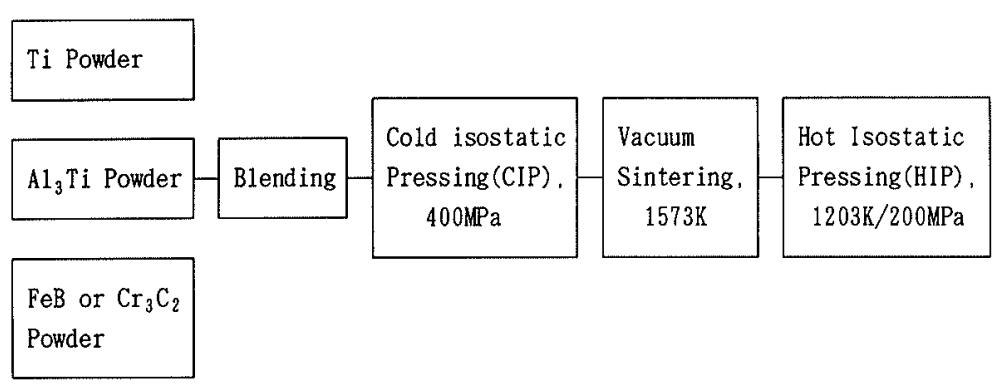

Fig. 1.

Processing steps for the fabrication of $\mathrm{BE} P / \mathrm{M}$ composite. will be described in this paper.

\section{Experimental Procedure}

The composites were made up using the processes of powder blending, cold isostatic pressing (CIP), vacuum sintering and hot isostatic pressing (HIP). As can be seen in Fig. 1, our proprietary technique was incorporated in this $\mathrm{BE} \mathrm{P} / \mathrm{M}$ method, in which matrix alloy-forming powders were blended with either boron-containing ceramic powder such as $\mathrm{FeB}$ or carbon-containing ceramic powder such as $\mathrm{Cr}_{3} \mathrm{C}_{2}$. During the sintering process, these ceramic powders are dissolved in the matrix and the dissolved and diffused $\mathrm{B}$ or $\mathrm{C}$ atoms react chemically with titanium to form titanium boride or titanium carbide in the matrix.

Two types of titanium-based MMC were fabricated using this proprietary technique. One type of composites, $\mathrm{Ti}-5 \mathrm{wt} \% \mathrm{Al}-2.5 \mathrm{wt} \% \mathrm{Fe}$ containing $15 \mathrm{wt} \%$ titanium boride, was made by blending extra low chlorine (ELCL) titanium powder $(\mathrm{Cl}<10 \mathrm{ppm}, \mathrm{O} \sim 1000 \mathrm{ppm},-100 \mathrm{mesh})$, $\mathrm{Al}_{3} \mathrm{Ti}$ master alloy powder $(-150 \mathrm{mesh})$ and $\mathrm{FeB}$ ceramic powder $(-325 \mathrm{mesh})$. The unreinforced $\mathrm{Ti}-5 \mathrm{Al}-2.5 \mathrm{Fe}$ matrix alloy, which belongs to high strength $\alpha-\beta$ type alloy and was developed for medical applications, ${ }^{16)}$ was also made ${ }^{17)}$ and tested to show differences from the composites. The other type of composites, Ti-5wt\%Al$13 \mathrm{wt} \% \mathrm{Cr}$ containing $10 \mathrm{wt} \%$ titanium carbide, were prepared using ELCL titanium powder, $\mathrm{Al}_{3} \mathrm{Ti}$ master alloy powder and $\mathrm{Cr}_{3} \mathrm{C}_{2}$ ceramic powder $(-325$ mesh). As will be described later, these titanium boride and titanium carbide reinforcements were identified to be TiB and $\mathrm{TiC}$, respectively. The $\mathrm{Al}_{3} \mathrm{Ti}$ and $\mathrm{FeB}$ ceramic powders were made in our laboratory by crushing the arc-melted button ingots. The titanium, $\mathrm{Al}_{3} \mathrm{Ti}$ master alloy powder and ceramic powder were blended in a V-shaped blender. The CIP'ing was done at $400 \mathrm{MPa}$ and vacuum sintering were performed for $14.4 \mathrm{ks}$ at $1573 \mathrm{~K}$. Sintered composites were finally HIP'ed at $1203 \mathrm{~K}$ and $200 \mathrm{MPa}$ to produce full dense composites. The oxygen content of the matrix alloys after HIP treatment was $1450 \mathrm{ppm}$.

The high temperature tensile tests were performed in the temperature range up to $923 \mathrm{~K}$ in a vacuum with $3.5 \mathrm{~mm}$ diameter by $16 \mathrm{~mm}$ gauge length specimens at a cross head speed of $0.1 \mathrm{~mm} / \mathrm{min}$.

\section{Results}

\subsection{Microstructure}

The microstructures of an unreinforced Ti-5Al-2.5Fe

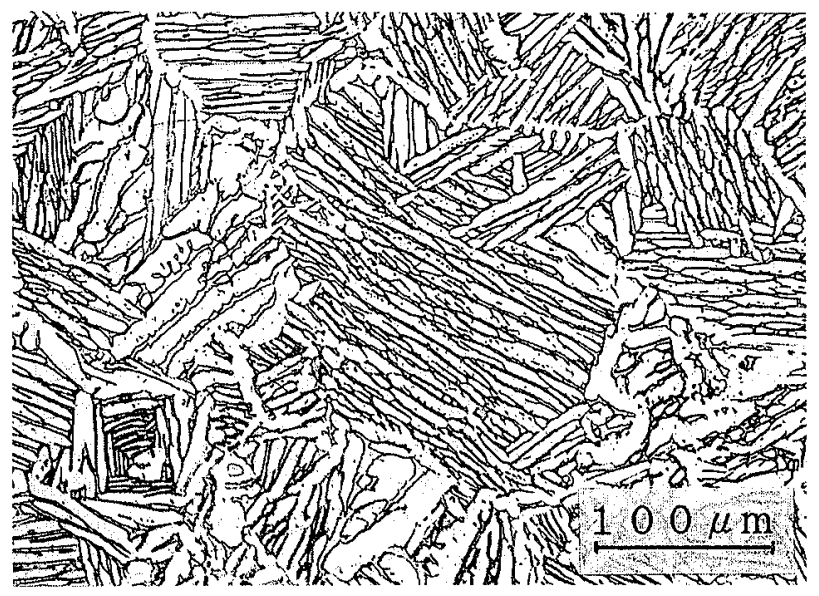

Fig. 2. Microstructure of unreinforced $\mathrm{BE} \mathrm{P/M} \mathrm{Ti-5Al-2.5Fe}$ in the HIP'ed condition.

and two types of the ceramic particulate reinforced titanium-based MMC are shown in Figs. 2, 3 and 4, respectively. The corresponding $\mathrm{X}$-ray diffraction patterns are also shown to indicate the phases present in the composites.

The microstructure of as-HIP'ed Ti-5Al-2.5Fe consists of coarse $\alpha-\beta$ two phase structure with a colony size of $\sim 150 \mu \mathrm{m}$ and massive $\alpha$ phase at the grain boundaries. The Ti-5Al-2.5Fe-based composite results in microstructure consisting of $\alpha-\beta$ two phase matrix with both needle-shaped and globular-shaped titanium borides. These two types of titanium borides were identified to be TiB by X-ray diffraction analysis, as shown in Fig. 3 . The reason why two different types of TiB were formed is not clear at this moment. It can be seen that the TiB reinforcements are distributed reasonably randomly in the matrix. There was no cluster of the TiB reinforcements seen throughout the specimen. The morphology of each alpha lath in the matrix differs significantly between the unreinforced alloy and composite, with the aspect ratio of the laths being markedly smaller in the composite. It seems that the length of lath is limited by the particulate spacing. Both the microstructure of unreinforced matrix alloy and the matrix microstructure of composite are in a state of thermally equilibrium in the as-HIP'ed condition and these will remain unchanged during the high temperature tests up to $923 \mathrm{~K}$. The optical microscopy observation and X-ray analysis of the Ti-5Al-13Cr-based composite in the as-HIP'ed condition revealed a matrix microstructure of primarily $\beta$ phase and randomly distributed globular-shaped TiC reinforcements, as has been shown in Fig. 4. Small peaks which correspond to the diffraction 

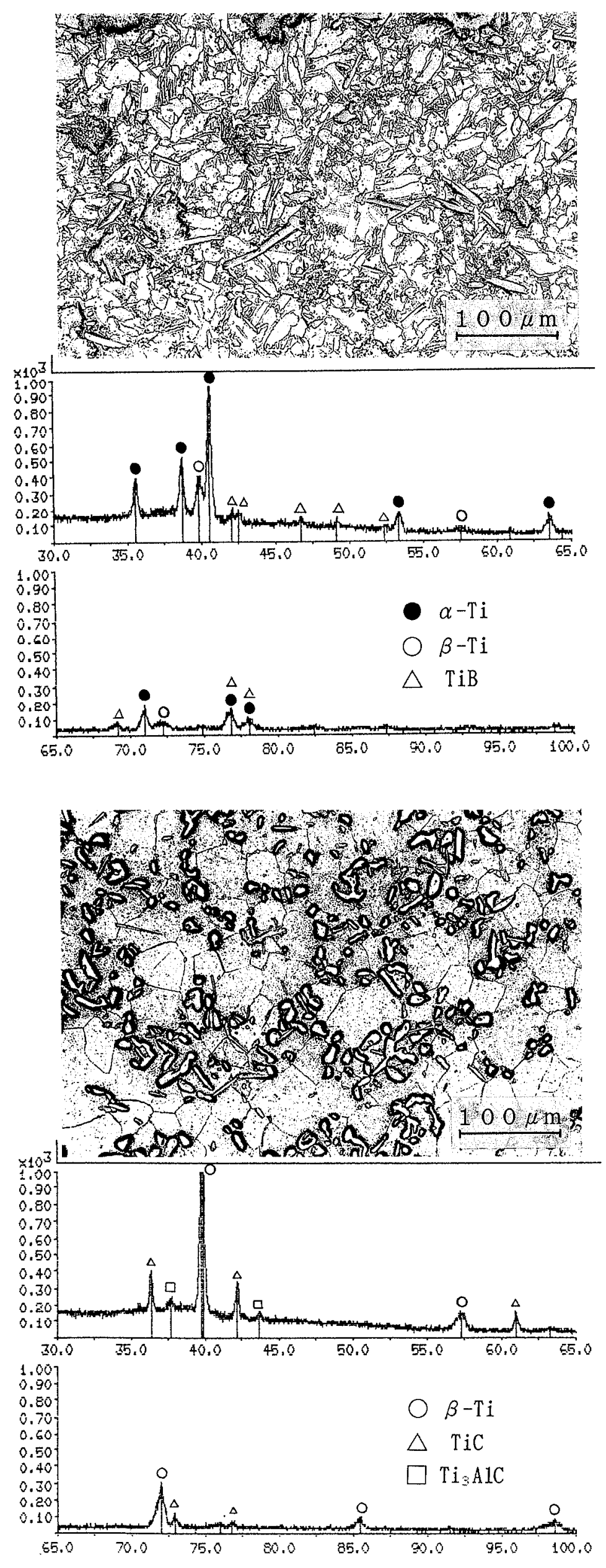

Fig. 3.

Microstructure of $\mathrm{BE} \mathrm{P} / \mathrm{M}$ Ti-5Al-2.5Fe-15TiB composite in the HIP'ed condition and the corresponding X-ray diffraction scan.
Fig. 4.

Microstructure of BE P/M Ti-5Al-13Cr-10TiC composite in the HIP'ed condition and the corresponding X-ray diffraction scan. 
Table 1. Summary of mechanical properties of composites and matrix alloys produced by the blended elemental $\mathrm{P} / \mathrm{M}$ route.

\begin{tabular}{|c|c|c|c|c|c|c|c|}
\hline & $\begin{array}{l}\text { Test temp. } \\
\left(\mathrm{K} /{ }^{\circ} \mathrm{C}\right)\end{array}$ & $\begin{array}{c}E \\
(\mathrm{GPa})\end{array}$ & $\begin{array}{l}0.2 \mathrm{YS} \\
(\mathrm{MPa})\end{array}$ & $\begin{array}{l}\text { UTS } \\
\text { (MPa) }\end{array}$ & $\begin{array}{c}\text { EL } \\
(\%)\end{array}$ & $\begin{array}{l}\mathrm{RA} \\
(\%)\end{array}$ & $\begin{array}{l}\text { Density } \\
\left(\mathrm{g} / \mathrm{cm}^{3}\right)\end{array}$ \\
\hline $\mathrm{Ti}-5 \mathrm{Al}-2.5 \mathrm{Fe}-15 \mathrm{TiB}$ & $\begin{array}{l}293 / 20^{*} \\
623 / 350 \\
773 / 500 \\
848 / 575 \\
923 / 650\end{array}$ & 151 & $\begin{array}{l}- \\
883 \\
683 \\
641 \\
368\end{array}$ & $\begin{array}{r}1092 \\
950 \\
803 \\
702 \\
399\end{array}$ & $\begin{array}{l}0.0 \\
1.3 \\
1.8 \\
2.0 \\
6.6\end{array}$ & $\begin{array}{r}0.7 \\
1.7 \\
3.5 \\
2.8 \\
13.8\end{array}$ & 4.485 \\
\hline $\mathrm{Ti}-5 \mathrm{Al}-13 \mathrm{Cr}-10 \mathrm{TiC}$ & $\begin{array}{l}293 / 20^{* *} \\
623 / 350^{* *} \\
773 / 500 \\
848 / 575 \\
923 / 650\end{array}$ & 125 & $\begin{array}{r}1111 \\
979 \\
835 \\
709 \\
300\end{array}$ & $\begin{array}{r}1111 \\
979 \\
868 \\
726 \\
380\end{array}$ & $\begin{array}{r}0.2 \\
0.2 \\
0.9 \\
2.1 \\
16.5\end{array}$ & $\begin{array}{r}0.7 \\
0.9 \\
3.0 \\
4.0 \\
23.8\end{array}$ & 4.608 \\
\hline $\mathrm{Ti}-5 \mathrm{Al}-2.5 \mathrm{Fe}$ & $\begin{array}{l}293 / 20 \\
623 / 350 \\
773 / 500 \\
923 / 650\end{array}$ & & $\begin{array}{l}850 \\
583 \\
455 \\
131\end{array}$ & $\begin{array}{l}947 \\
725 \\
584 \\
147\end{array}$ & $\begin{array}{l}14.3 \\
13.9 \\
19.9 \\
35.9\end{array}$ & $\begin{array}{l}35.0 \\
41.5 \\
52.7 \\
70.6\end{array}$ & 4.462 \\
\hline
\end{tabular}

* Specimen failed before $0.2 \%$ yield strength was obtained.

** Specimen failed before ultimate tensile strength was obtained.

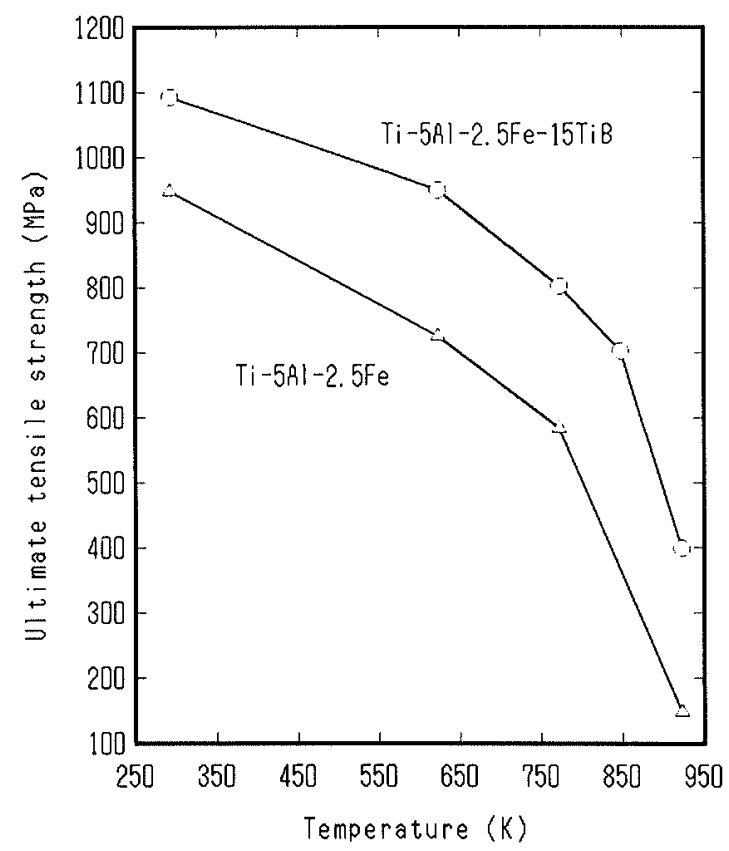

Fig. 5. The temperature dependence of the ultimate tensile strength of $\mathrm{BE} \mathrm{P} / \mathrm{M}$ Ti-5Al-2.5Fe-I $5 \mathrm{TiB}$ composite and $\mathrm{BE} \mathrm{P} / \mathrm{M}$ Ti-5Al-2.5Fe matrix alloy.

from $\mathrm{Ti}_{3} \mathrm{AlC}$ were also observed in the $\mathrm{X}$-ray diffraction scan.

No obvious interaction zone is visible in both composites at the resolution available in optical and scanning microscopy. However, in the case of BE P/M $\mathrm{Ti}-6 \mathrm{Al}-4 \mathrm{~V} / \mathrm{TiC}$ composite, the formation of the annulus of $\mathrm{Ti}_{2} \mathrm{C}$ arround the $\mathrm{TiC}$ reinforcement has been observed when using transmission electron microscopy. ${ }^{11)}$

\subsection{Mechanical Properties}

The mechanical properties of the two composites, i.e., $\mathrm{Ti}-5 \mathrm{Al}-2.5 \mathrm{Fe}-15 \mathrm{TiB}$ and $\mathrm{Ti}-5 \mathrm{Al}-13 \mathrm{Cr}-10 \mathrm{TiC}$ are given in Table 1, and are presented graphically in Figs. 5 and 6, respectively. The baseline data for unreinforced Ti-5Al-2.5Fe matrix alloy and property data for other high temperature alloys produced by the conventional

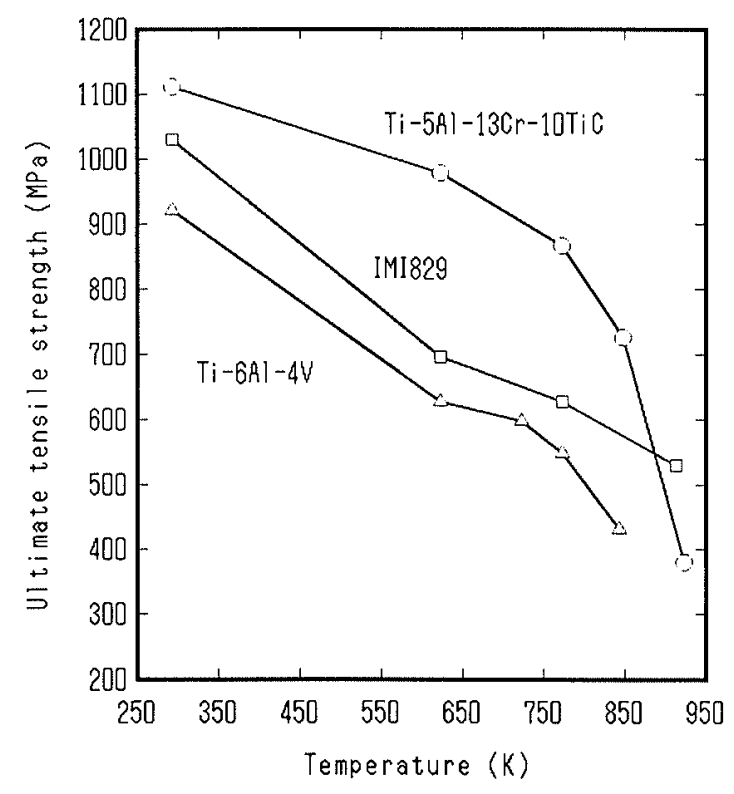

Fig. 6. The temperature dependence of the ultimate tensile strength of $\mathrm{BE} \mathrm{P} / \mathrm{M} \mathrm{Ti}-5 \mathrm{Al}-13 \mathrm{Cr}-10 \mathrm{TiC}$ composite, and $\mathrm{BE} \mathrm{P} / \mathrm{M}$ Ti-6Al-4V and IMI 829 alloys.

BE $\mathbf{P} / \mathbf{M}$ route ${ }^{17)}$ are also included in these Table and Figures.

The Ti-5Al-2.5Fe-15TiB composite can achieve remarkably higher elastic modulus at room temperature, $151 \mathrm{GPa}, 32 \%$ higher than that of unreinforced Ti-6Al-4V, $114 \mathrm{GPa} .{ }^{18)}$ Although the Ti-5Al-13Cr$10 \mathrm{TiC}$ composite also showed a higher elastic modulus, $125 \mathrm{GPa}$, than the unreinforced $\mathrm{Ti}-6 \mathrm{Al}-4 \mathrm{~V}$, this value is considerably lower than the $\mathrm{Ti}-5 \mathrm{Al}-2.5 \mathrm{Fe}-15 \mathrm{TiB}$ composite. This result will partly be attributed to the fact that the Ti-5Al-13Cr matrix is almost completely $\beta$ type alloy, as has been revealed by X-ray analysis, and it is known that the $\beta$ type alloys generally exhibit lower elastic modulus ${ }^{17)}$ compared to those for $\alpha-\beta$ type alloys such as $\mathrm{Ti}-6 \mathrm{Al}-4 \mathrm{~V}$ and $\mathrm{Ti}-5 \mathrm{Al}-2.5 \mathrm{Fe}$.

The yield and tensile strength for the Ti-5Al-2.5Fe$15 \mathrm{TiB}$ composite were superior to those for the unreinforced matrix alloy in the whole temperature range 

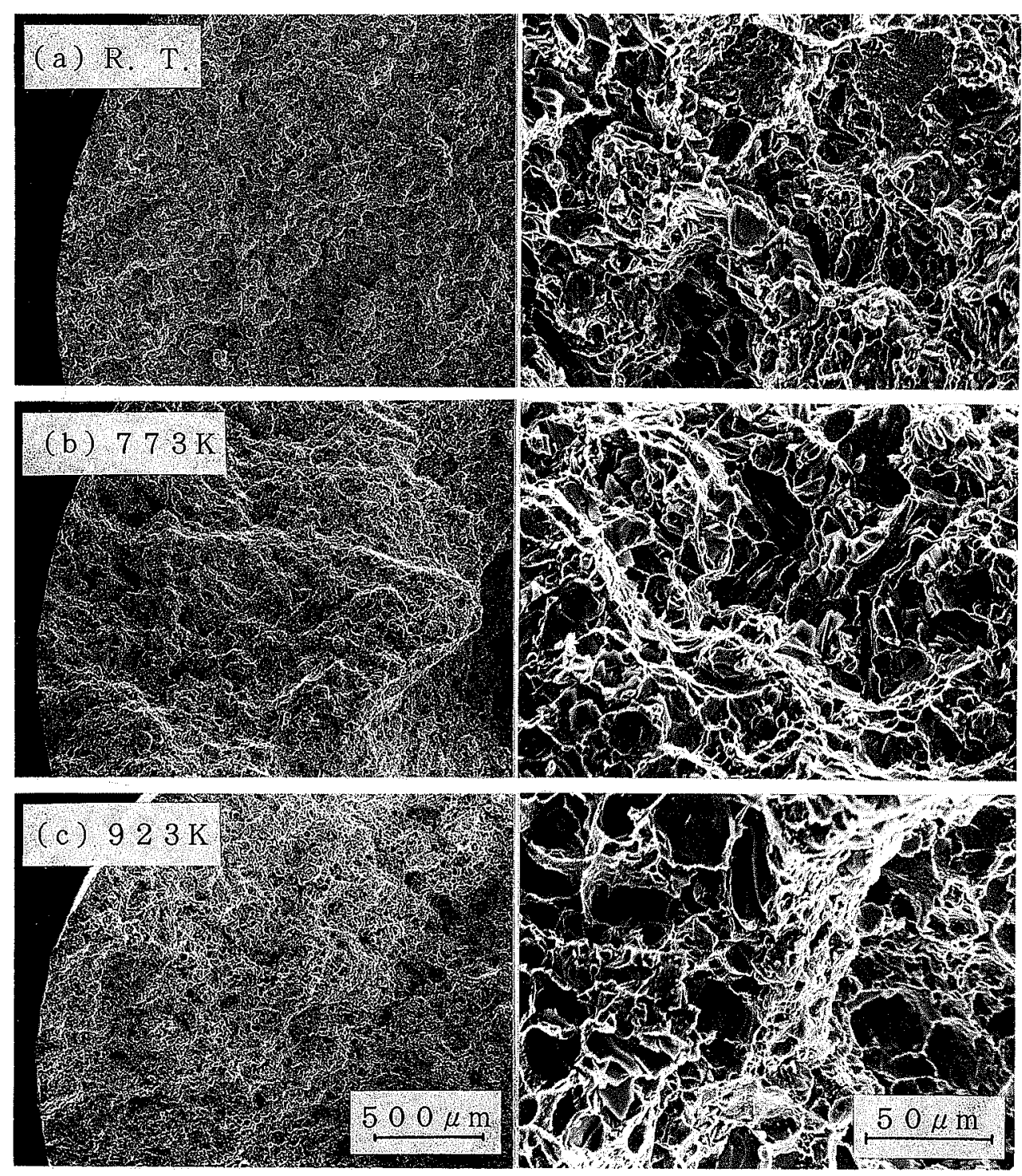

Fig. 7. Scanning electron micrographs at low and high magnification of the fracture surfaces taken from $B E$ $\mathrm{P} / \mathrm{M}$ Ti-5 $\mathrm{Al}-13 \mathrm{Cr}-10 \mathrm{TiC}$ composite tested at room and at higher temperatures.

examined. Although high temperature tensile data for Ti-5Al-13Cr baseline alloy are not taken yet, comparison with those for other high temperature titanium alloys such as $\mathrm{Ti}-6 \mathrm{Al}-4 \mathrm{~V}$ and IMI829 (Ti-5.5Al-3.5Sn-3Zr$0.3 \mathrm{Mo}-1 \mathrm{Nb})$ reveals that the $\mathrm{Ti}-5 \mathrm{Al}-13 \mathrm{Cr}-10 \mathrm{TiC}$ composite also have higher tensile strength.

These results demonstrate that the uniform distribution of relatively large-sized ceramic particulates which have superior mechanical properties at high temperatures relative to the matrix alloy is an effective method for improving the elastic modulus and the tensile strength of conventional titanium alloy. However, the ductility of composites was significantly lower than that of the matrix alloy. At room temperature the composites failed in a brittle manner before ultimate tensile strength was obtained. At the highest temperature, $923 \mathrm{~K}$, measurable ductility was obtained for both composites, as shown in Table 1.

\subsection{Fractography}

Scanning electron micrographs taken from fracture surfaces of the $\mathrm{Ti}-5 \mathrm{Al}-13 \mathrm{Cr}-10 \mathrm{TiC}$ composite are shown in Fig. 7. Irrespective of the test temperatures, the fracture surface consists of the small portions of cleavage fracture and the main regions of dimpled fracture. Optical micrographs of the cross section of tensile test specimens in the vicinity of the fracture area reveal the cracking within the TiC particulates, as shown in Fig. 8. These observations indicate that the cleavage fracture seen on the fracture surface corresponds to the fracture of the TiC particulate. In addition, it seems most importantly that the fracture within the $\mathrm{TiC}$ particulate occured prior to the dimpled ductile fracture of the surrounding matrix alloy. This may be indicative of sufficient bonding at the interface between the particulate and the matrix alloy.

Figure 9 shows the fracture behavior of the Ti-5Al$2.5 \mathrm{Fe}-15 \mathrm{TiB}$ both at room and at elevated temperatures. As is the case for the $\mathrm{Ti}-5 \mathrm{Al}-13 \mathrm{Cr}-10 \mathrm{TiC}$ composite, the fracture initiated owing to cracking within the grobularshaped $\mathrm{TiB}$ in preference to the dimpled ductile fracture of the matrix alloy. 


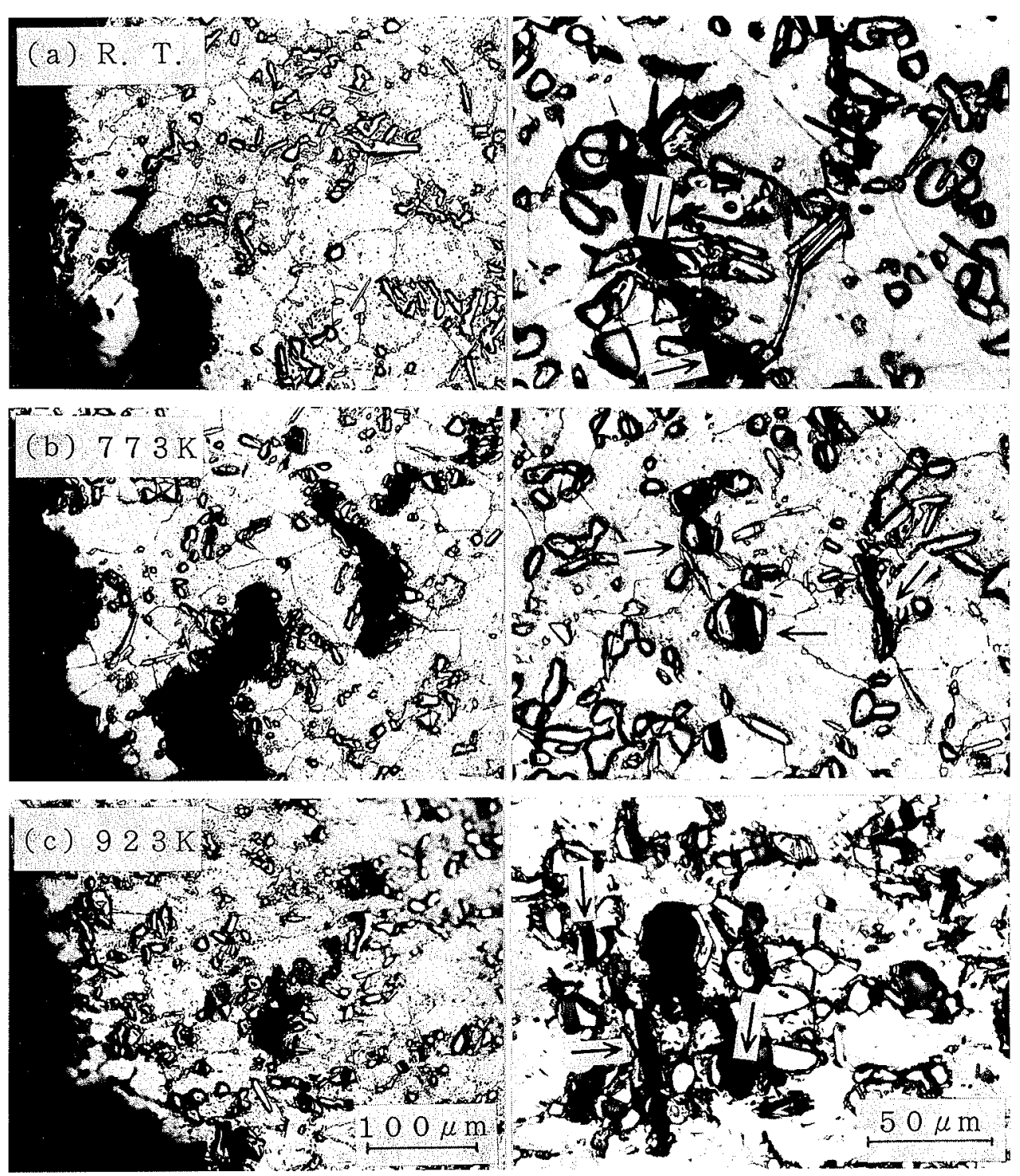

Fig. 8. Optical micrographs of a cross sectional area both through (left-hand side micrographs) and away from the fracture surface (right-hand side micrographs) taken from BE P/M Ti-5Al-13Cr-10TiC composite tested at room and higher temperatures, showing the fracture of the TiC particulates (indicated by arrows) prior of failure of the surrounding matrix.

\section{Discussion}

For the fabrication of the titanium-based MMC using the $\mathrm{BE} P / \mathrm{M}$ route, there is another technique for dispersing ceramic particulate reinforcements. This technique is simply to blend the intended ceramic powder or particulates such as $\mathrm{TiC}$ and $\mathrm{TiB}_{2}$ with the matrix alloy-forming powders. However, a preliminary experiment done at our laboratory and the report ${ }^{10)}$ by other researchers revealed that the commercially available very small ceramic particulates $(\sim 1 \mu \mathrm{m})$ tend to agglomerate, and the agglomerated cluster of particulates was found to be the origin of the premature failure during the tensile test even at higher temperatures. To avoid the occurrence of the agglomeration, it is necessary to use relatively larger ceramic particulates. But these are not beneficial for improving composite properties. It is also said ${ }^{10)}$ that this "simple blending" technique can be limited by interfacial wettability problems, because the ceramic particulates generally have an oxide surface layer which can affect the adherence of the particulate to the matrix alloy and therefore lead to failure at the interface. ${ }^{10)}$ Our proprietary "internal reaction" technique can avoid these two intrinsic problems associated with the "simple blending" technique. As seen in Figs. 2 and 3, this technique enables $\mathrm{TiB}$ or $\mathrm{TiC}$ particulate reinforcements to be dispersed reasonably uniformly in the matrix, which means that there is no macroscopic agglomeration of the $\mathrm{FeB}$ or $\mathrm{Cr}_{3} \mathrm{C}_{2}$ particulates in the powder-mixing stage. In addition, because these reinforcements are formed in-situ, contamination at the reinforcement/matrix interface does not occur and hence excellent bonding at the interface can be achieved, ${ }^{13}$ ) which enables the sufficient load transfer from the matrix to the ceramic reinforcements.

The actual strength of the ceramic particulate is generally very poor primarly due to the existence of stress-concentrating flaws such as voids within the ceramic. Contrary to this, the ceramic particulates which were formed in-situ during the sintering process is 


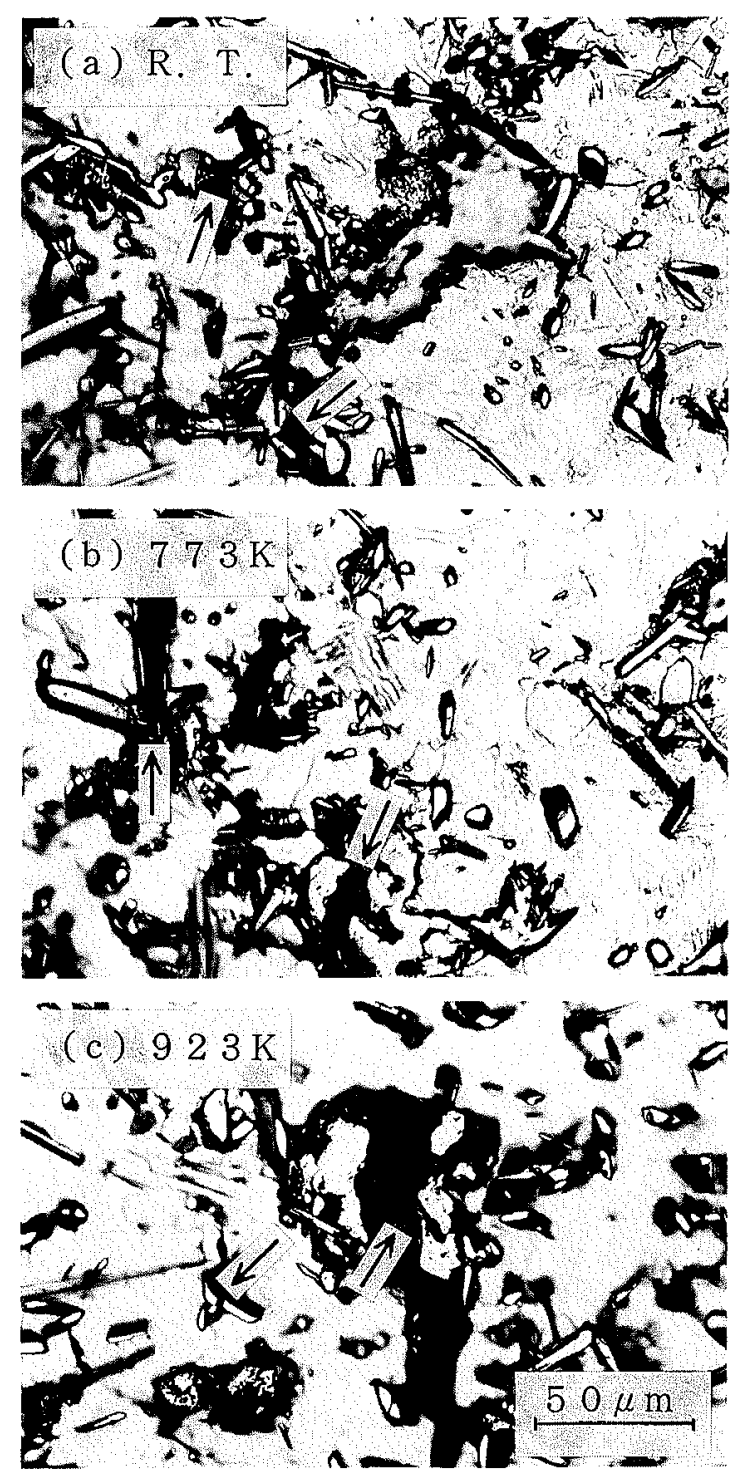

Fig. 9. Optical micrographs of a cross sectional area away from the fracture surface taken from $\mathrm{BE} \mathrm{P} / \mathrm{M} \mathrm{Ti}$ $5 \mathrm{Al}-2.5 \mathrm{Fe}-15 \mathrm{TiC}$ composite tested at room and higher temperatures, showing the fracture of the TiB particulates (indicated by arrows) prior to failure of the surrounding matrix.

expected to have almost no macroscopic flaws, since it is reported that the ceramic formed in this manner has been proved to be single crystals. ${ }^{9,13}$ )

Therefore, these three advantages, i.e., reasonably randomly distributed particulate reinforcements, excellent bonding at the reinforcement/matrix interface and the lack of macroscopic flaws within the ceramic reinforcement, would mainly be responsible for the increase in flow stress observed in the present titaniumbased MMC.

As shown in Figs. 2 and 3, the microstructure of the matrix has been changed from one with similarly aligned $\alpha$ laths in the unreinforced material to one with relatively randomly oriented low aspect ratio $\alpha$ laths. This microstructural change is known to lead to higher strength by a reduced slip length. ${ }^{17,19)}$ Thus, the refined matrix microstructure compared with that of the unreinforced material would also be responsible for the increased strength of the composites. ${ }^{11)}$

The tensile ductility of the composites produced in this study showed almost zero at room temperature. Because the facture initiated within the ceramic particulates and is followed by the ductile failure of the surrounding matrix alloy, it may be reasonable to consider that the size, morphology and distribution of the reinforcement is mainly respoinsible for the performance of the composite under tensile condition. In fact, it is reported that the tensile strength of the $\mathrm{TiC}$ reinforced $\mathrm{Ti}$ composites is mostly sensitive too the size of reinforcement particle. ${ }^{9)}$ Therefore it will be suggested that further refinement of the ceramic reinforcement through fabrication modifications such as the use of much smaller starting powder materials, may lead to additional improvement in the room temperature tensile ductility of these composites.

\section{Conclusion}

Two types of the titanium-based metal matrix composites, $\mathrm{Ti}-5 \mathrm{Al}-2.5 \mathrm{Fe}-15 \mathrm{TiB}$ and $\mathrm{Ti}-5 \mathrm{Al}-13 \mathrm{Cr}-10 \mathrm{TiC}$, were produced using the proprietary blended elemental $\mathrm{P} / \mathrm{M}$ route, whereby ceramic powders such as $\mathrm{FeB}$ and $\mathrm{Cr}_{3} \mathrm{C}_{2}$ were used in an attempt to disperse either $\mathrm{TiB}$ or $\mathrm{TiC}$ particulate reinforcements in-situ in the matrix.

The conclusions obtained are summarized as follows:

(1) It seemed likely that there was no agglomerated cluster of $\mathrm{FeB}$ or $\mathrm{Cr}_{3} \mathrm{C}_{2}$ in the powder-mixing stage, and $\mathrm{TiB}$ of both needle and globular morphology and TiC of only globular morphology were found to be formed and distributed reasonably randomly in the matrix.

(2) The elastic modulus and tensile strength of these two composites were greatly increased compared to those for unreinforced matrix alloys, demonstrating that the uniform distribution of ceramic particulates in the matrix is an effective method for improving the mechanical properties of conventional titanium alloys.

(3) No ductility was found for both composites at room temperature, but some measurable ductility was obtained at temperatures above $623 \mathrm{~K}$. The tensile fracture originated from the cracking within the ceramic reinforcements, followed by the ductile failure in the surrounding matrix alloy.

\section{Acknowledgment}

The authors wish to express their appreciation to Mr. S. Miura of the Chichibu Research Laboratory, Showa Denko K.K. for his valuable discussions and helpful technical comments.

\section{REFERENCES}

1) D. Eylon, S. Fujishiro, P. J. Postans and F. H. Froes: J. Met., 36 (1984), No. 11, 55.

2) J. Wadworth and F. H. Froes: J. Met., 41 (1989), No. 5, 12.

3) S. F. Baumann, P. K. Brindly and S. D. Smith: Metall. Trans. A, 21 A (1990), 1559.

4) G. Das: Metall. Trans. A, 21A (1990), 1571.

5) S. M. Russ: Metall. Trans. A, 21A (1990), 1595

6) S. Jansson, H. E. Deve and A. G. Evans: Metall. Trams. A, 22A (1991), 2975.

7) W. Takahashi, M. Okada, Y. Shida and M. Nakanishi: 
Tetsu-to-Hagané, 77 (1991), 1336.

8) A. R. C. Westwood: Metall. Trans. A, 19A (1988), 749.

9) Y. Lin, R. H. Zee and B. A. Chin: Metall. Trans. A, 22A (1991), 859.

10) M. L. Adams, S. L. Kampe and L. Christodoulou: Int. J. Powder Met., 26 (1990), 105.

11) H. H. Loretto and D. G. Konitzer: Metall. Trans. A, 21A (1990), 1579.

12) S. Abkowitz and P. Weihrauch: Adv. Mater. Process., (1989), No. 7,31 .

13) L. Yuxiong, B. Jing, L. Douxing and P. Dehai: To be published in Proc. 92 ISCMC.

14) Z. Quan, Pu. M. Xiaonan, W. Bende and L. Feng: Private
Communication, (1991).

15) F. H. Froes and D. Eylon: Titanium, Science and Technology, ed. by G. Lütjering, U. Zwiker and W. Bunk DGM, Oberursel, (1985), 267.

16) J. Breme: Proc. 6th World Conf. Titanium, Vol. 1, Société Française de Métallurgie, Paris, (1988), 57.

17) M. Hagiwara, X. Kawabe, Y. Kaieda and S. Miura: ISIJ Int., 31 (1991), 922.

18) S. Lampman: Metals Handbook, Vol. 2, 10th ed., ASM, Ohio, (1991), 592.

19) M. Peters, A. Gysler and G. Lüetjering: Titanium '80, ed. by H. Kimura and O. Izumi, AIME, Warrendale, (1980), 1777. 